\title{
Hart e Dworkin falam sobre a mesma coisa?: apontamentos sobre as condições do debate*
}

\section{Are hart and dworkin talking about the same thing?: notes on the terms of the debate}

\section{Resumo}

O presente artigo tem por fim analisar a possibilidade do debate teórico entre Hart e Dworkin. Propõe-se uma investigação sobre as consequências do reconhecimento do fato de que, enquanto a teoria de Hart é descritiva e geral, a de Dworkin é predominantemente avaliativa e particular. Após a exposição do significado desses traços na obra dos dois autores, algumas razões serão expostas no sentido de fundamentar a viabilidade da contraposição entre suas teorias. A dimensão descritiva da proposta dworkiniana, a necessidade de relativização do caráter particular dessa proposta e a constatação da centralidade do problema da relação entre o direito e a moral para as duas teorias sustentará a defesa da utilidade e significância do estudo das dissensões entre os dois autores.

Palavras-chave: Hart. Dworkin. Metodologia jurídica.

\begin{abstract}
This article aims to analyze the possibility of theoretical debate between Hart and Dworkin. We propose a research on the consequences of the fact that while Hart's theory is descriptive and general, Dworkin's one is predominantly evaluative and particular. After exposure of the meaning of these features in the work of the two authors, some are explained in order to substantiate the feasibility of contrast between their theories. The descriptive dimension of the dworkinian proposal, the need to relativize the particular character of such proposal and the centrality of the problem of the relationship between law and morality for the two theories sustain the defense of the usefulness and significance of the study of the contrasts between the two authors.
\end{abstract}

Keywords: Hart. Dworkin. Legal methodology. 


\section{Introdução}

Data de 1961 a publicação de $O$ conceito de direito, obra de H. L. A. Hart que reformulou amplamente os marcos estruturais do positivismo jurídico. Superando grande parte das objeções dirigidas às ideias de John Austin, a proposta de Hart focou-se na investigação das condições de existência do fenômeno jurídico, ao mesmo tempo em que proveu uma análise das características principais da atividade jurisdicional que se realiza no âmbito de um sistema jurídico desenvolvido.

Essa obra fez surgir vasta literatura crítica desde os primeiros anos que se seguiram a sua publicação. Tanto positivistas quanto não positivistas se viram obrigados a se debruçar seriamente sobre os argumentos expostos por Hart, uma vez que, pela profunda e bem estruturada mudança que propunha e talvez pela posição de destaque ocupada pelo autor no meio acadêmico inglês ${ }^{2}$, seu trabalho foi alçado, à medida que se difundia, à condição de leitura obrigatória para aqueles que se dedicavam ao estudo do direito.

Nesse contexto, foi já em 1963 que Ronald Dworkin trouxe à luz o seu Judicial Discretion, ensaio no qual expôs contundente crítica à descrição feita por Hart do modo de proceder dos juízes diante de casos controversos. Foi esse trabalho que, juntamente com outros do mesmo autor - destacadamente, The Model of Rules I de 1967 -, lançou as bases daquilo que viria a ser um dos tópicos mais relevantes da filosofia do direito do século XX: o debate Hart-Dworkin.

Pode-se dizer que tal debate vem sendo, desde o seu surgimento, explorado em suas diferentes facetas e consequências. De fato, desde questões de filosofia política até outras de epistemologia, passando por questionamentos mais fundamentais de filosofia do direito, foram expostas e dimensionadas no contexto das supostas dissensões entre os dois autores. Ocorre que, muito embora um sem número de estudiosos tenha se debruçado sobre as mais complexas minúcias da obra de Hart e Dworkin, por muito tempo nenhum deles chegou a questionar a própria possibilidade do debate. $\mathrm{O}$ que se quer com isso dizer é que, de modo geral, as investigações sobre os fundamentos e inconsistências das diferentes opiniões que

2 Ao tempo da publicação de O conceito de direito, Hart titularizava a cátedra de Teoria Geral do Direito na Universidade de Oxford. dão substância às discussões ofuscaram uma questão mais zetética e, por isso mesmo, mais fundamental: Hart e Dworkin falam sobre a mesma coisa?

Esse problema ganha relevância após a publicação, no ano de 1994, do pós-escrito de Hart ao seu O conceito de direito. Nessa ocasião, tendo já defendido o caráter descritivo de sua teoria, escreveu o autor:

Não me parece muito claro por que razão, ou mesmo de que modo, poderia haver qualquer conflito significativo entre empreendimentos tão diferentes quanto minhas próprias concepções da teoria do direito e as de Dworkin. Assim, boa parte da obra de Dworkin, inclusive $O$ império do direito, é dedicada à elaboração de méritos comparativos de três descrições diferentes da forma como o direito ("decisões políticas passadas") justifica a coerção, produzindo assim três formas diferentes de teoria do direito, que ele denomina 'convencionalismo', 'pragmatismo jurídico' e 'o direito como integridade'. Tudo o que ele escreve sobre esses três tipos de teoria tem grande interesse e importância como contribuição a uma teoria do direito justificativa e avaliativa $[\ldots]^{3}$.

Em linhas gerais, esse trecho parece indicar a necessidade do seguinte questionamento: uma vez que a teoria de Dworkin se compromete com juízos justificativos e normativos - ainda que não exclua, e até defenda, enunciações descritivas - e se volta, com nos diz o próprio autor, para uma cultura jurídica particular - a anglo-americana $^{4}$-, não seria correto dizer que não há qualquer possibilidade de conflito entre ela e a teoria de Hart, já que esta é, ou ao menos se propõe a ser, descritiva e ge$\mathrm{ral}^{5}$ ? É essa a questão que se passa a analisar.

\section{Os pontos de discórdia}

Antes, porém, é útil que se faça um breve esboço dos principais pontos da suposta dissensão entre os dois autores. Ao que nos parece, esses pontos podem ser sintetizados em torno de dois focos de indagações ${ }^{6}$.

3 HART, H. L. A. O conceito de direito. São Paulo: WMF Martins Fontes, 2009. p. 311-312.

4 DWORKIN, Ronald. O império do direito. São Paulo: Martins fontes, 2007. p. 127.

5 HART, H. L. A. O conceito de direito. São Paulo: WMF Martins Fontes, 2009. p. 309.

6 Essa divisão entre dois objetos relativamente distintos das discussões entre Hart e Dworkin foi inspirada pelas análises de Scott J. Shapiro, em especial por seu The "Hart-Dworkin" debate: a short guide for the perplexed (2007). 
O primeiro deles diz respeito à norma de reconhecimento proposta por $\mathrm{Hart}^{7}$. A questão é saber se sua estrutura permite que seja classificada como um aporte para a compreensão do direito como simples fato. Seria ela sensível a elementos morais? Se a resposta a essa pergunta for positiva, é preciso saber de que modo e em que medida. Tais pontos têm ainda desdobramentos mais fundamentais que tocam as seguintes questões: deve-se investigar se existe em nossa prática jurídica algo que nos permita atribuir um poder discricionário aos juízes para que decidam alguns casos do direito com base em critérios que não sejam propriamente jurídicos. Questiona-se se é isso que eles devem fazer, como propõe Hart, quando algum caso incide no âmbito da "textura aberta" do direito ${ }^{8}$. A investigação desses problemas, deve-se dizer, está na base da construção de qualquer teoria jurídica minimamente ampla.

O segundo conjunto de indagações deflui do seguinte problema central: como se fazem possíveis as discordâncias teóricas sobre o direito ${ }^{9}$ ? Em outras palavras, é necessário compreender como se dão e que consequências geram as divergências que têm por objeto os critérios últimos e fundamentais de identificação e distinção do fenômeno jurídico. Conforme se percebe, esse segundo conjunto de problemas, ao menos aparentemente, coloca um profundo desafio para certos autores positivistas, à medida que esses, como o faz $\operatorname{Hart}^{10}$, sustentam a existência da regra de reconhecimento em sua aceitação por parte daqueles que participam do sistema jurídico.

Assim colocados os pontos fundamentais daquilo que tem sido chamado de debate entre Hart e Dworkin, podemos retomar a investigação sobre a possibilidade do conflito entre as teorias dos dois autores.

\section{Compreendendo o problema}

\subsection{Sobre a natureza da teoria de Dworkin}

Para começar a respondê-la, é necessário localizar

7 HART, H. L. A. O conceito de direito. São Paulo: WMF Martins Fontes, 2009. p.122-123.

8 HART, H. L. A. O conceito de direito. São Paulo: WMF Martins Fontes, 2009. p. 161-176.

9 DWORKIN, Ronald. O império do direito. São Paulo: Martins fontes, 2007. p. 8.

10 HART, H. L. A. O conceito de direito. São Paulo: WMF Martins Fontes, 2009. p.122-123. com exatidão o foco desse problema no projeto de Dworkin. Sabe-se que um postulado fundamental de sua teoria é a noção de interpretação construtiva. Sobre o significado dessa ideia, diz o autor:

[...] a interpretação construtiva é uma questão de impor um propósito a um objeto ou prática, a fim de torná-lo o melhor exemplo possível da forma ou do gênero aos quais se imagina que pertençam. [...] Ela propõe uma forma de ver o que é interpretado - uma pratica social ou uma tradição, tanto quanto um texto ou uma pintura - como se este fosse o produto de uma decisão de perseguir um conjunto de temas, visões ou objetivos, uma direção em vez de outra ${ }^{11}$.

Ainda segundo o autor, esse modo de interpretar abarca três diferentes etapas: a pré-interpretativa, a interpretativa e a pós-interpretativa ${ }^{12}$. A primeira delas tem por fim a fixação do objeto da interpretação, seu "conteúdo experimental" ${ }^{13}$. A segunda se volta à busca por uma “justificativa geral para os principais elementos da prática identificada na etapa pré-interpretativa" ${ }^{14}$. Por fim, na última etapa o interprete irá decidir aquilo que a prática requer - ou seja, o modo como deve solucionar alguma questão que lhe é apresentada - à luz da justificativa a ela atribuída na etapa interpretativa ${ }^{15}$.

Ocorre que é possível separar dois momentos interpretativos distintos - ou seja, duas aplicações da interpretação construtiva - na obra de Dworkin. O primeiro deles tem por fim a produção de uma concepção do direito que se revele como a melhor e mais adequada justificativa política para a prática jurídica como um todo. $\mathrm{O}$ segundo momento surge do interior da concepção que é, segundo Dworkin, o produto da primeira interpretação, ou seja, o direito como integridade ${ }^{16}$. Essa interpretação tem por fim não a busca por uma concepção do direito, mas sim a resolução de novos casos à luz da concepção já encontrada.

11 DWORKIN, Ronald. O império do direito. São Paulo: Martins fontes, 2007. p. 63-64.

12 DWORKIN, Ronald. O império do direito. São Paulo: Martins fontes, 2007. p. 81-84.

13 DWORKIN, Ronald. O império do direito. São Paulo: Martins fontes, 2007. p. 81.

14 DWORKIN, Ronald. O império do direito. São Paulo: Martins fontes, 2007. p. 81.

15 DWORKIN, Ronald. O império do direito. São Paulo: Martins fontes, 2007. p. 165-166.

16 DWORKIN, Ronald. O império do direito. São Paulo: Martins fontes, 2007. p. 271-332. 
Essa distinção é fundamental para fixarmos uma base para nossas investigações: os questionamentos sobre a efetiva existência de discordâncias importantes entre Hart e Dworkin têm por foco a correção - e mesmo a possibilidade - daquilo que chamamos de primeiro momento interpretativo. Ou seja, é o meio através do qual se dá a construção de uma teoria/concepção do direito que está em jogo, e não aquilo que uma certa concepção requer. A partir disso, devemos passar a enfrentar os pressupostos da objeção que estamos analisando.

Em primeiro lugar, a teoria de Dworkin é mesmo avaliativa/justificativa/normativa? Logo na introdução de seu Taking rights seriously, o autor nos fornece uma indicação no sentido de que "[...] uma teoria geral do direito deve ser ao mesmo tempo normativa e conceitual" ${ }^{17}$. Após dizer isso, passa a analisar os principais temas que uma tal teoria deve abordar, sem, contudo, fazer menção às nuances avaliativas e descritivas de seu próprio empreendimento teórico.

De fato, é somente n'O império do direito que a afirmação acima citada ganha sentido por meio do desenvolvimento da compreensão do direito como um conceito interpretativo ${ }^{18}$. Como já vimos, a concretização dessa ideia se dá através da busca, em diferentes etapas, de um sentido para a prática do direito como um todo. Assim, a par dessa estruturação mais ampla, a pergunta que formulamos no parágrafo anterior deve adquirir uma forma mais concreta e direta, no sentido de pôr a questão de saber se nas três etapas interpretativas propostas para a construção de uma concepção do direito podemos encontrar tanto elementos descritivos quanto avaliativos.

A etapa pré-interpretativa é essencialmente descritiva. Como já dito, é nessa etapa que se dá a seleção do material que servirá de objeto à interpretação, e tal seleção, como nos indica a ideia de comunidade interpretativa $^{19}$, se baseia em um alto grau de consenso sobre o conteúdo da prática a ser interpretada. Assim, a atividade do intérprete nessa etapa se reduzirá, em grande medida, a investigação desse consenso, fato que autoriza

17 DWORKIN, Ronald. Taking rights seriously. Cambridge: Harvard University Press, 1997. p. 7. (tradução nossa).

18 DWORKIN, Ronald. O império do direito. São Paulo: Martins fontes, 2007. p. 81-84.
Hart, não sem algum exagero, a assinalar que muito do que Dworkin diz sobre essa etapa da interpretação “[...] parece endossar o ponto de vista segundo o qual sua concepção exige [...] algo muito semelhante a uma norma de reconhecimento que identifique as fontes competentes do direito" 20 .

Ao que nos parece, porém, os traços descritivos da atividade interpretativa proposta por Dworkin cessam por aí. Pode-se até dizer, ainda que sob risco de simplificação excessiva, que a dimensão de adequação da etapa interpretativa abarca e fomenta, à medida que também parte da exigência de um certo grau de consenso - muito inferior ao exigido pela etapa pré-interpretativa, é verdade - sobre os limites necessários à justificativa proposta à prática pela interpretação ${ }^{21}$, algum tipo de atividade não essencialmente valorativa, mas o mesmo não pode sequer ser cogitado em relação aos passos seguintes da interpretação construtiva, ou seja, a dimensão da justificação e a etapa pós-interpretativa.

Nesses passos, com efeito, o intérprete deverá basear-se em asserções mais substantivas sobre que conjuntos de princípios morais e políticos mostram a prática interpretada sob sua melhor luz. É dizer, buscará ele atribuir a esta prática um sentido que permita que a ela seja dado seguimento de forma consistente, ou seja, de acordo com a percepção de uma unidade explicativa fundamental cujo conteúdo floresça dos traços mais relevantes daquilo que se interpreta ${ }^{22}$.

Diante dessas colocações, parece coerente com as pretensões da teoria de Dworkin a ideia de que “[...] seu aspecto descritivo explica a presente estrutura da instituição judicial [...]”, enquanto que “[...] seu aspecto normativo oferece uma justificação política para essa estrutura [...]" 23, de modo que assim reste estabelecida "a inseparabilidade dos momentos descritivos e justificativos" ${ }^{24}$.

20 HART, H. L. A. O conceito de direito. São Paulo: WMF Martins Fontes, 2009. p.343.

21 DWORKIN, Ronald. O império do direito. São Paulo: Martins fontes, 2007. p. 83.

22 DWORKIN, Ronald. The Concept of Unenumerated Rights. Chicago Law Review, Chicago, v. 59, p. 381-432, 1992. p. 391-394.

23 DWORKIN, Ronald. Taking rights seriously. Cambrigde: Harvard University Press, 1997. p. 123. (tradução nossa)

24 RODRÍGUEZ, César. La decisión judicial: el debate Hart Dworkin. Santafé de Bogotá: Siglo del Hombre, 1997. p. 63. (tradução nossa) 


\subsection{Hart e a possibilidade de uma teoria descritiva}

Fixada uma das premissas da questão que estamos a analisar - de fato, a teoria de Dworkin é tanto avaliativa quanto descritiva -, devemos focar nossas atenções em seu outro pressuposto: o caráter descritivo da doutrina de Hart. Sobre esse ponto, diz o autor:

\begin{abstract}
Minha exposição é descritiva no sentido de que é moralmente neutra e não tem fins de justificativa: não busca justificar, com base em fundamentos morais ou outros, ou recomendar formas e estruturas que aparecem em minha descrição geral do direito, embora uma compreensão clara destas constitua, a meu ver, uma condição preliminar importante para qualquer critica moral frutífera do direito ${ }^{25}$.
\end{abstract}

Embora nos indique uma direção na investigação do problema, esse trecho não é suficiente para darmos como certa a hipótese nele defendida. Assim, ao invés de buscarmos saber o que dizem sobre a questão os autores envolvidos diretamente no debate que analisamos - Hart e Dworkin -, iremos nos debruçar sobre a questão mais profunda que parece estar por trás desse ponto da discussão: é possível que uma teoria do direito seja tão somente descritiva?

Brian Leiter entende que sim, e sua argumentação, pela força que tem, merece ser por nós considerada. Qualificando a teoria de Dworkin como proponente de um "conceito normativo de direito" ${ }^{26}$, o autor defende que tal teoria, à medida que nega a possibilidade de uma filosofia do direito puramente descritiva com base na ideia de que o fenômeno jurídico somente pode ser compreendido a partir da atribuição a ele de um valor (point), ignora o fato de que alguém possa "descrever o valor que tem uma prática para seus participantes sem, contudo, engajar-se na prática de valoração" ${ }^{27}$. Vejamos como se desenvolve essa ideia.

Usualmente, diz Leiter, as criticas que se voltam às pretensões descritivas se baseiam na equivocada noção de que a verdade banal (banal truth) segundo a qual

25 HART, H. L. A. O conceito de direito. São Paulo: WMF Martins Fontes, 2009. p. 309-310.

26 LEITER, Brian. Beyond the Hart/Dworkin Debate: the Methodological Problem in Jurisprudence. American Journal of Jurisprudence, v. 48, p. 17-51, 2003. p. 20.

27 LEITER, Brian. Beyond the Hart/Dworkin Debate: the Methodological Problem in Jurisprudence. American Journal of Jurisprudence, v. 48, p. 17-51, 2003. p. 22. (tradução nossa)
“[...] valorações são componentes indispensáveis e decisivos na seleção ou formação de quaisquer conceitos para uso na descrição de aspectos da vida humana, tais como o direito e a ordem jurídica" ${ }^{28}$ compromete o intérprete com visões morais e políticas específicas que refletem tão somente a sua subjetividade. O erro dessa posição, segue Leiter, é ignorar a distinção fundamental entre valores epistêmicos (epistemic values) e valores morais (moral values) ${ }^{29}$.

O primeiro tipo de valores surgiria como mero corolário das ordinárias aspirações que devem pautar a construção de qualquer teoria, é dizer, a adequação de método, a simplicidade conceitual, a consistência explicativa e coisas análogas. Os valores morais, em contrapartida, seriam respostas a questões propriamente valorativas; questões que, muito embora possam ter respostas com algum grau de uniformidade consensual, exigem a tomada de posição a respeito de posturas morais substantivas. A título de exemplo, tome-se a decisão sobre que instituições políticas são mais capacitadas para a proteção de direitos ou que ocasiões justificam a desobediência às leis postas pelo Estado.

À luz dessa distinção, a questão que, segundo Leiter, deve ser colocada é a seguinte: os julgamentos indispensáveis à construção de uma teoria do direito devem fazer referência, além dos valores epistêmicos, também aos valores morais? A resposta que dá não poderia ser mais clara:

[...] a teoria descritiva do direito aceita a verdade banal quando responde 'não' a essa questão. Entende que as normas epistêmicas são, por si só, suficientes para demarcar o fenômeno jurídico para fins de interpretá-lo ${ }^{30}$.

Diante desses argumentos, portanto, nos parece correto reconhecer a possibilidade de uma teoria do direito eminentemente descritiva, desde que não perca-

28 LEITER, Brian. Beyond the Hart/Dworkin Debate: the Methodological Problem in Jurisprudence. American Journal of Jurisprudence, v. 48, p. 17-51, 2003. p. 24. (tradução nossa)

29 LEITER, Brian. Beyond the Hart/Dworkin Debate: the Methodological Problem in Jurisprudence. American Journal of Jurisprudence, v. 48, p. 17-51, 2003. p. 25. (tradução nossa)

30 LEITER, Brian. Beyond the Hart/Dworkin Debate: the Methodological Problem in Jurisprudence. American Journal of Jurisprudence, v. 48, p. 17-51, 2003. p. 25. (tradução nossa) 
mos de vista a ideia atribuída por Stephen Guest a Mark Greenberg ${ }^{31}$ segundo a qual não é dado a ninguém “explicar fatos empíricos exclusivamente em termos empíricos, de modo que algo fora da verdade empírica se faz necessário" ${ }^{32}$, algo que pode ser chamado, na linha do que propõe Leiter, de valores epistêmicos ${ }^{33}$.

\section{Hart e Dworkin falam sobre a mesma coisa?}

Percorrido esse caminho, podemos finalmente adentrar ao âmago da questão que nos ocupa: dado que a teoria de Hart é alegadamente descritiva - e, como estivemos a analisar, é concebível a existência de uma tal teoria - e geral, ela pode conflitar com a de Dworkin, que é descritivo-avaliativa e particular?

Philip Soper inclina-se para responder negativamente essa questão. Caracterizando de forma ligeiramente distinta aquilo que chamamos de caráter geral e particular dos projetos teóricos, respectivamente, de Hart e Dworkin, o autor defende que, onde quer que surja um conflito entre dois desses tipos de teorias, "tal se dará na forma de contra-exemplo e não de contra-teoria" ${ }^{34}$. Isso quer dizer, basicamente, que a teoria de Dworkin deveria ser analisada como uma aplicação específica, um exercício de concretização das ideias que foram abstrata e genericamente defendidas por $\operatorname{Hart}^{35}$.

O próprio $\mathrm{Hart}^{36}$, conforme já citamos, parece corroborar essa tese em seu pós-escrito. A ela também faz referência César Rodríguez quando alude ao ponto de vista segundo o qual “[...] a proposta dos dois autores

31 GREENBERG, Mark. How Facts Make Law. Legal Theory, n. 05-22, 2004.

32 GUEST, Stephen. How to Criticize Ronald Dworkin's Theory of Law. Analysis, v. 69, n. 2, p. 1-13, abr. 2009. p. 3. (tradução nossa)

33 A perder isso de vista, estaríamos sujeitos a equívocos do tipo que, a nosso ver, Shapiro comete quando defende que "[...] os propósitos específicos de um sistema jurídico são questões de fato social". SHAPIRO, Scott J. The "Hart-Dworkin" Debate: a Short Guide for Perplexed. Working Paper, n. 34, fev. 2007. p. 47. (tradução nossa)

34 SOPER, Philip E. Legal Theory and The Obligation of a Judge: the Hart/Dworkin dispute. Michigan Law Review, Michigan, n. 75, p. 473-519, 1976-1977. p. 474. (tradução nossa)

35 LEITER, Brian. Beyond the Hart/Dworkin Debate: The Methodological Problem in Jurisprudence. American Journal of Jurisprudence, v. 48, p. 17-51, 2003. p. 15-16. tins Fontes, 2009. p. 311. seriam linhas paralelas que, por definição, nunca se cruzam. Pelo contrário, podem completar-se mutuamente; Dworkin, por exemplo, poderia oferecer uma justificação das práticas que Hart descreve, e vice-versa" ${ }^{37}$. Um exemplo de uma situação na qual seria ilusória a existência de conflito entre as teorias pode nos ajudar a entender melhor o que tal ideia representa.

De acordo com Dworkin, a conexão entre o direito e a moralidade é forte, ou seja, necessária ${ }^{38}$. Desse modo, a verdade de uma proposição jurídica - seu pertencimento a certo ordenamento - estaria sempre condicionada a sua conformação a certos critérios morais. Já segundo Hart, e em especial após a publicação do pós-escrito, a relação entre esses dois campos é meramente contingente, o que quer dizer que os meios de identificação do fenômeno jurídico apenas incorporam mandamentos morais à medida que outros critérios factuais o recomendem ${ }^{39}$. Assim, poderiam dizer os partidários da posição que estamos analisando, é esse um exemplo claro de um caso em que o conflito entre as duas teorias é apenas aparente. Isso porque a postura de Dworkin, de acordo com a qual a relação entre direito e moral é necessária, apenas se referiria ao sistema jurídico norte-americano, de modo que não negaria -antes confirmaria- a posição hartiana no sentido de que, em alguns sistemas, tal relação pode dar-se de modo necessário.

Em que pese a notável força de tais argumentos, não é essa a posição que sustentamos. A nosso ver, poderosas razões dão base à defesa da utilidade e pertinência do estudo do debate entre Hart e Dworkin como uma forma de contraposição teórica efetiva, ou seja, uma contraposição entre empreendimentos investigativos que, compartilhando em boa medida um mesmo objeto, se chocam de modo substancial em alguns pontos fundamentais. Vejamos, em linhas gerais, algumas dessas razões.

\subsection{Dworkin também descreve}

Em primeiro lugar, devemos lembrar que não

37 RODRÍGUEZ, César. La decisión judicial: el debate Hart Dworkin. Santafé de Bogotá: Siglo del Hombre, 1997. p. 46. (tradução nossa)

38 DWORKIN, Ronald. A matter of principle. Cambridge: Harvard University Press, 1985. p. 146-166.

39 HART, H. L. A. O conceito de direito. São Paulo: WMF Martins Fontes, 2009. p. 334-335. 
só a teoria de Hart tem pretensões descritivas. De fato, também Dworkin se propõe a explicar, por exemplo, o funcionamento das instituições judiciárias, o modo como procedem os juízes na decisão dos mais diversos tipos de casos e a maneira como se estruturam as expectativas dos membros da comunidade a respeito daquilo que devem decidir os julgadores. Tudo isso é muito bem ilustrado pelo fato de que as primeiras objeções que esse autor dirigiu à Hart têm por objeto aquilo que César Rodriguez chamou de "pilares descritivos do positivismo" ${ }^{40}$, ou seja, a ideia de discricionariedade judicial, o teste de pedigree e os limites das obrigações jurídicas ${ }^{41}$.

Nesse sentido, aquilo que chamamos, no item $\mathrm{n}^{\circ} 2$, de primeiro foco de discussão entre Hart e Dworkin gira em torno de um problema descritivo fundamental: quando fazem uso de princípios para a resolução de casos controversos, os juízes encaram esses padrões como parte do direito? Hart, como se sabe, entende que não, ou seja, defende que os juízes atuam, nessas hipóteses, com base no poder discricionário de que são titulares. Dworkin não concorda com esse ponto de vista e a crítica que a ele dirige está ancorada em sua falta de plausibidade em termos descritivos.

Com efeito, a objeção formulada pelo autor tem por inspiração um questionamento sobre a razão que justificaria a pressuposição de acordo com a qual os juízes mentem quando dizem que estão, nos casos em que incorrem em discordâncias substanciais, trilhando um caminho rumo à solução que lhes parece ser exigida pelo direito. Não há motivos para não acreditar, aponta Dworkin, que eles de fato baseiam suas ações na crença de que pode haver uma decisão que seja, do ponto de vista jurídico, melhor que outras ${ }^{42}$.

No mais, não se deve perder de vista o já aludido fato de que o direito como integridade - concepção teórica defendida por Dworkin -, se propõe a ser o resultado de uma interpretação construtiva, ou seja, o produto de uma argumentação que visa dar sentido à prática jurídica

40 RODRÍGUEZ, César. La decisión judicial: el debate Hart Dworkin. Santafé de Bogotá: Siglo del Hombre, 1997. p. 47. (tradução nossa)

41 DWORKIN, Ronald. Judicial Discretion. The Journal of Philosophy, v. 60, n. 21, p. 624-638, out. 1963.

42 DWORKIN, Ronald. O império do direito. São Paulo: Martins fontes, 2007. p. 46. como um todo a partir de sua melhor luz ${ }^{43}$. Não é preciso grande esforço para perceber que tal atividade pressupõe a definição aproximada dos limites empíricos da prática que se interpreta, atividade que tem inegável dimensão descritiva.

\subsection{O traço particular da teoria de dworkin deve ser relativizado}

A segunda razão diz respeito à ideia de que Dworkin desenvolveu seu empreendimento teórico tendo em vista apenas as ordens jurídicas vigentes nos países anglo-americanos. A nosso ver, é um exagero tomar literalmente a afirmação segundo a qual a teoria de Dworkin é particular, extraindo dela a impossibilidade de que sirva como parâmetro para descrição e avaliação de qualquer outro sistema de direito que não os expressamente considerados pelo autor. A esse respeito, adverte César Rodríguez:

[...] muito embora o objeto de reflexão de Dworkin seja o direito norte-americano - e, em um plano secundário, o direito inglês -, os elementos e as conclusões de sua teoria podem ser estendidos em boa medida a outros ordenamentos jurídicos, especialmente àqueles que contam com um sistema de controle de constitucionalidade forte como o dos Estados Unidos 44

Com isso não se quer dizer, por óbvio, que as ideias de Dworkin não precisam ser adaptadas para que possam ser aplicadas a sistemas diferentes. No que diz respeito à ordem jurídica brasileira, por exemplo, é significativo o fato de que, ao contrário do que se dá nas culturas expressamente mencionadas na obra do autor, a doutrina do stare decisis ${ }^{45}$ tem força relativa, enquanto que o direito

43 GUEST, Stephen. Ronald. Dworkin. California: Stanford University Press, 2012. p. 62-85.

44 RODRÍGUEZ, César. La decisión judicial: el debate Hart Dworkin. Santafé de Bogotá: Siglo del Hombre, 1997. p. 47. (tradução nossa)

45 Essa ideia, que em nossa língua toma o nome de "regra do precedente", é fundamental para a compreensão dos sistemas jurídicos anglo-saxônicos filiados ao common law. De fato, nesses sistemas as decisões judiciais constituem-se em genuínas fontes de direito, de modo que boa parte daquilo que nos ordenamentos de origem romano-germânica são questões de legislação positiva, naqueles outros figuram como questões de interpretação de decisões judiciais passadas. Aludindo ao exemplo inglês, René David bem ilustra essa ideia: "Na falta de certa autoridade reconhecida aos precedentes, não haveria, falando-se propriamente, um 
de origem legislativa parece ter maior prestígio. Esses e outros traços dos diferentes sistemas normativos ao redor do mundo, é inegável, trazem consequências importantes para a aplicabilidade da proposta dworkiniana; não são, contudo, capazes de impedir de modo absoluto a utilização dessa teoria como recurso explicativo e avaliativo das diversas manifestações do fenômeno jurídico ${ }^{46}$.

\subsection{A relação direito-moral}

A essas duas razões se soma outra ainda mais forte. Estreitamente relacionado com o argumento anterior, esse último deriva do reconhecimento do fato de que um dos principais problemas abordados por Dworkin é comum a todas as ordens normativas que, tendo se desenvolvido para além de relações particulares isoladas, reivindicam a coerção estatal para o cumprimento de suas medidas. Trata-se da busca pela definição dos meios de identificação do fenômeno jurídico e, consequentemente, da compreensão da influência exercida pelas prescrições morais no âmbito desses critérios ${ }^{47}$.

O ponto importante aqui é o seguinte: dado que essa é uma questão que surge em relação a qualquer manifestação - ainda que bastante primitiva e embrionária - do direito, deve ser também considerada um dos objetos fundamentais da teoria geral de Hart. De fato, Hart estruturou seu pensamento a partir da ideia central de acordo com a qual compete à regra secundária de reconhecimen-

direito inglês, mas apenas soluções específicas, decididas, na verdade, pelo arbítrio do juiz. O direito inglês só pôde desenvolver-se e tornar-se um sistema porque, desde uma época bastante antiga - desde o século XIII -, existiram coletâneas de jurisprudência e porque os juízes levaram muito em consideração os precedentes". DAVID, René. $O$ direito inglês. São Paulo: Martins Fontes, 1997. p. 13.

46 A aludida diferença entre a importância atribuída às fontes do direito no sistema brasileiro e naqueles de origem anglo-saxônica, por exemplo, não apresenta qualquer obstáculo à aplicação da teoria de Dworkin, uma vez que o autor dedicou-se a análise não só da força dos precedentes, mas também a investigação daquilo que os juristas norte-americanos chamam de interpretação estatutária (statutory interpretation). Ver DWORKIN, Ronald. O império do direito. São Paulo: Martins fontes, 2007. p. 377-424; Taking rights seriously. Cambridge: Harvard University Press, 1997. p. 105-106.

47 Sobre as diversas posições teóricas em face da relação entre o direito e a moral, ver ALEXY, Robert. La institucionalización de la justicia. Granada: Editorial Comares, 2005; ALE$\mathrm{XY}$, Robert. The argument from injustice. Oxford: Oxford University Press, 2002. to identificar aquilo que compõe o direito de certa comunidade ${ }^{48}$. O que há de fundamental quanto a tal regra é o fato de que, segundo o autor, ela não deve incorporar de modo necessário nenhuma dimensão moral, ou seja, a presença de elementos de moralidade como meio de identificação de padrões jurídicos se dará, quando muito, apenas contingencialmente ${ }^{49}$.

A justificar a nossa terceira razão para defender que há entre Hart e Dworkin uma contraposição teórica importante, tem-se que a relação entre o direito e a moral é um ponto fundamental dos debates entre os autores. Quer isso dizer que aquilo que dá sentido à grande parte das questões que são abordadas sob a sigla das dissensões entre esses teóricos está presente em toda e qualquer manifestação institucional do direito.

É a partir dessa perspectiva, portanto, que podemos atestar que os traços particularistas e avaliativos da teoria de Dworkin, bem como o caráter descritivo e geral da proposta de Hart, jamais ofereceram qualquer obstáculo à contraposição entre a ideia hartiana segundo a qual a moralidade não tem função necessária na identificação dos mandamentos jurídicos que vigoram em certa comunidade e a máxima dworkiniana de que tais mandamentos apenas podem ser distinguidos através do conjunto de princípios morais que seja produto de uma interpretação que dê a prática jurídica como um todo o melhor sentido possível.

\section{Conclusão}

O debate entre Hart e Dworkin converteu-se, nas últimas décadas, em um dos tópicos fundamentais da teoria do direito. Ocorre, porém, que a questão mais profunda sobre a possibilidade dessa contraposição teórica foi comumente negligenciada. A esse respeito, o desafio é investigar se o caráter descritivo e geral da teoria de Hart e as dimensões avaliativas e particulares da proposta dworkiniana constituem um impedimento para a oposição das ideias dos dois autores. Em outras palavras, o que interessa é saber se os dois empreendimentos teóricos versam sobre os mesmos problemas.

48 HART, H. L. A. O conceito de direito. São Paulo: WMF Martins Fontes, 2009. p.122-123.

49 HART, H. L. A. O conceito de direito. São Paulo: WMF Martins Fontes, 2009. p.334-335. 
A nosso ver, são três as razões fundamentais que devem orientar a solução de tal questão. Em primeiro lugar, deve-se dar atenção ao fato de que também a teoria de Dworkin tem traços descritivos importantes, o que fica claro quando se tem em vista a primeira das etapas interpretativas sugeridas pelo autor no âmbito da interpretação construtiva. Conforme dito, esse é um dado que aproxima sua teoria, em termos de objeto de investigação, da obra de Hart.

Em segundo lugar, o traço particularista do projeto dworkiniano deve ser relativizado. Os sistemas jurídicos em vigor pelo mundo - mesmo aqueles de inspiração história distinta, como é o caso, de um lado, dos sistemas romano-gêrmanicos, e de outro, dos anglo-saxônicos -, compartilham alguns traços fundamentais, o que nos permite dizer que as ideias de Dworkin também podem ter aplicação, ainda que com certas ressalvas, a ordens jurídicas diferentes da norte-americana.

Por fim, deve ser enfatizado o fato de que ambos os autores atribuem grande importância à investigação dos meios de identificação do fenômeno jurídico e, como não poderia deixar de ser, também à influencia exercida pelos padrões de moralidade sobre tais meios. Como se disse, esse é um problema que surge em qualquer sistema jurídico, o que nos autoriza a dizer, portanto, que a diferença entre a teoria dos dois autores no que diz respeito à abrangência (particular/geral) não é capaz de interferir nas discussões sobre esse ponto.

Diante dessas razões, só nos resta uma conclusão: Hart e Dworkin falam sim, ao menos em uma grande me$\operatorname{dida}^{50}$, sobre a mesma coisa.

\section{Referências}

ALEXY, Robert. La institucionalización de la justicia. Granada: Editorial Comares, 2005.

ALEXY, Robert. The argument from injustice. Oxford: Oxford University Press, 2002.

50 Com essa ressalva queremos reafirmar a existência de algumas distinções que parecem defluir naturalmente dos diferentes pontos de partida e finalidades das duas teorias. Exemplo notável disso é a grande atenção que Hart dispensa aos requisitos de existência de um sistema jurídico, teorização que não se encontra em Dworkin. Sobre isso, ver: HART, H. L. A. O conceito de direito. São Paulo: WMF Martins Fontes, 2009. p. 103-129; e RODRÍGUEZ, César. La decisión judicial: el debate Hart - Dworkin. Santafé de Bogotá: Siglo del Hombre, 1997. p. 46.
DAVID, René. O direito inglês. São Paulo: Martins Fontes, 1997.

DWORKIN, Ronald. A matter of principle. Cambrigde: Harvard University Press, 1985.

DWORKIN, Ronald. Judicial Discretion. The Journal of Philosophy, v. 60, n. 21, p. 624-638, out. 1963.

DWORKIN, Ronald. O império do direito. São Paulo: Martins Fontes, 2007.

DWORKIN, Ronald. Taking rights seriously. Cambrigde: Harvard University Press, 1997.

DWORKIN, Ronald. The Concept of Unenumerated Rights. Chicago Law Review, Chicago, v. 59, p. 381-432, 1992.

GREENBERG, Mark. How facts make law. Legal Theory, n. 05-22, 2004.

GUEST, Stephen. How to criticize Ronald Dworkin's theory of law. Analysis, v. 69, n. 2, p. 1-13, abr. 2009.

GUEST, Stephen. Ronald Dworkin. California: Stanford University Press, 2012.

HART, H. L. A. O conceito de direito. São Paulo: WMF Martins Fontes, 2009.

LEITER, Brian. Beyond the Hart/Dworkin debate: the methodological problem in jurisprudence. American Journal of Jurisprudence, v. 48, p. 17-51, 2003.

RODRÍGUEZ, César. La decisión judicial: el debate Hart - Dworkin. Santafé de Bogotá: Siglo del Hombre, 1997.

SHAPIRO, Scott J. The "Hart-Dworkin" debate: a short guide for perplexed. Working Paper, n. 34, fev. 2007.

SOPER, Philip E. Legal theory and the obligation of a judge: the Hart/Dworkin dispute. Michigan Law Review, Michigan, n. 75, p. 473-519, 1976-1977. 